\title{
El cristianismo ante el siglo XXI en América Latina Una reflexión desde las víctimas ${ }^{1}$
}

\author{
Jon Sobrino S.J.
}

Resumen

Ante este siglo XXI real, el cristianismo tiene que preguntarse qué hacer. Lo primero ya lo hemos hecho: pasar juicio sobre este mundo desde las víctimas. Pero, más allá de eso, hay que preguntarse qué ser y qué hacer en y con ese mundo. En este sentido, la perspectiva del autor es la de los pobres y víctimas de este mundo $y$, aceptando las novedades alrededor del cambio de siglo, quiere desmitificarlas un poco. Así, visto desde las víctimas, el siglo XXI ya empezó en 1989, con la caída del este. Y por lo que toca al cristianismo, su gran novedad -que sigue siendo lo más novedoso- comenzó en 1968 con Medellín.

\section{Introducción}

El final de siglo tiene un simbolismo de calendario, digámoslo así, y es normal que a ello se desee unir otro tipo de simbolismo más cualitativo: los cambios, novedades y desafíos. En ese contexto nos preguntan cómo abordar el siglo XXI desde el cristianismo en América Latina, y esto es lo que vamos a intentar exponer. Pero quisiera hacer antes dos breves observaciones. La primera es que mi perspectiva es la de los pobres y víctimas de este mundo. $Y$ la segunda es que, aceptando las novedades alrededor del cambio de siglo, quisiera desmitificarlas un poco. Así, visto desde las víctimas, el siglo XXI ya empezó en 1989, con

1. Ponencia emitida en el XIX Congreso de Teología, "El cristianismo ante el siglo XXI", organizado por la Asociación Juan XXIII, Madrid, 12 de septiembre de 1999. 
la caída del este. $Y$ por lo que toca al cristianismo, su gran novedad - que sigue siendo lo más novedoso-comenzó en 1968 con Medellín.

\section{La realidad de los pobres ante el siglo XXI}

El siglo XXI ya comenzó en 1989 con la caída del socialismo: el norte contra el sur ( $X$. Gorostiaga). Y, sin fijar fechas, comenzó con el neoliberalismo como "la venganza de los ricos contra los pobres" (J. Comblin). El informe del Programa de Naciones Unidas para el Desarrollo (PNUD) da a conocer anualmente el estado de la pobreza en el mundo, que da también una idea de cómo está el continente latinoamericano. Aunque los datos puedan ser conocidos, por ahí hay que empezar, si se adopta la perspectiva de las víctimas.

\subsection{Lo más flagrante: la aberración de la si- tuación mundial}

De diversas formas se suele hablar del siglo XXI. Me refiero ahora a la que desea comunicar la sensación de que estamos ante lo realmente nuevo, lo que suele transmitirse o comunicando que hemos llegado al fin de la historia o, en formulación casi contraria, que la historia está prácticamente empezando ahora con los fenómenos novedosísimos de globalización... Y, sobre todo, me refiero a la que quiere dar la sensación de que, como decía Jesús al hablar del reino, "el tiempo se ha cumplido, el reino de Dios se acerca, cambien de mente y crean en el evangelio". Se acerca o ha llegado ya el eu-aggelion del mercado.

Pues bien, no hay duda de que hay novedades en este cambio de milenio, pero un mínimo de honradez y de rigor científico exigen analizarlas y verificar qué de evangelio traen las dichas novedades, y si éste es para las mayorías pobres o para las minorías opulentas, si es para Lázaro o para Epulón.

Lo hacemos con sentimiento de impotencia, pero intentémoslo una vez más. En 1991, el año en los albores del siglo XXI real, el PNUD causó conmoción al hacer pública la situación de pobreza y desarrollo de nuestro mundo. Baste decir que los datos eran aberrantes, tanto por lo que toca a la especie humana, es decir, su capacidad de simplemente sobrevivir, como por lo que toca a la familia humana, es decir, su capacidad para vivir fraternalmente unos con otros. Y desde entonces, aun con algunos avances sectoriales, las cosas no han ido a mejor, sino a peor.
Según el informe recién publicado en julio de este año, el 20 por ciento de la población de mayores ingresos posee el 86 por ciento del producto interno bruto, el 82 por ciento de los mercados mundiales de exportación, el 68 por ciento de la inversión extranjera directa y el 74 por ciento de las líneas telefónicas. Las tres personas más ricas del mundo tienen unos activos que superan el PIB de los países más subdesarrollados, en los que viven más de 600 millones de seres humanos.

Con ser esto aberrante, lo que más me interesa recalcar al reflexionar en términos de tiempo histórico es que en 80 países, la renta es hoy inferior a la de hace una década. Y por lo que toca a la totalidad de la humanidad, en 1960, la relación entre ricos y pobres era de 1 a 30; en 1991 era de 1 a 60 y en 1997 llegó a ser de 1 a 74. Según el Consejo Económico y Social (ECOSOC) de la ONU, en los últimos 25 años se ha duplicado el número de pobres en el mundo - problema que ahora afecta también, y de manera novedosa, a los países ricos-. En el este asiático, en los dos próximos años, los pobres pasarán de los 40 millones actuales a casi 100 millones. En Indonesia, el número de personas que vivían con menos de un dólar al día en 1997 era de 13 millones; para finales de este año llegarán a ser 34 millones. En América Latina se ha bajado de un crecimiento del 5.3 por ciento en 1997 al 2.6 por ciento en el presente año. África continúa siendo el continente "perdedor". Para 1998 se preveía un crecimiento económico del 4.5 por ciento, pero no superará el 2.2 por ciento.

Los informes hablan del inmenso control de las multinacionales sobre el mundo entero: las diez compañías más importantes de telecomunicaciones controlan el 86 por ciento del mercado... Las multinacionales no sólo generan, sino que también destruyen puestos de trabajo. Según el instituto Panos, solamente en 1998, Indonesia perdió ocho millones de puestos de trabajo; el desempleo se ha duplicado en Tailandia y Corea del Sur; y en México 800000 campesinos han perdido sus tierras a causa de la liberalización y de los acuerdos de integración regional... Se calcula en 2200 billones de dólares la deuda externa que las 41 naciones más pobres deberían restituir a occidente.

El informe también menciona algunas de las aberraciones éticas del estrenado siglo XXI. Se invierte más dinero en la investigación de productos 
cosméticos o en la maduración retardataria del tomate que en las obtención de la vacuna contra el sida (cada día contraen esa enfermedad 16000 personas) o la malaria. Como consecuencia del Mitch, las multinacionales fruteras se hicieron con miles de trabajadores y trabajadoras en Honduras: 15 días de sueldo y a la calle. A pesar de ello, las multinacionales se ufanan de favorecer el desarrollo en el tercer mundo $y$ de hacer crecer puestos de trabajo.

"Qué decir ante este siglo XXI? A Michel Camdessus, presidente del Fondo Monetario Internacional, no pareció sacudirle la visión global del planeta: "La prosperidad de un país es responsabilidad de él mismo. La creación de empleo, la lucha contra la pobreza y la reducción de las diferencias entre hombres y mujeres dependen, en definitiva, del crecimiento, y, es más, de un crecimiento de calidad". Claro que no hay que olvidar sus famosas palabras en Lille, el 27 de marzo de 1992, a los representantes de la banca mundial después de leer Lucas 4, I6ss: "ustedes son hoy los que llevan la buena noticia a los pobres". Otros mostraron más lucidez: lo que está ocurriendo es "la globalización de la pobreza", la amenaza del aumento, no de la disminución de la pobreza. De ahí que "o progresamos juntos o nos hundiremos juntos" (Francisco Paolo Falci). Y Kofi Annan, Secretario General de la ONU, criticó duramente que la ayuda oficial al desarrollo se encuentra a su nivel más bajo en los últimos 50 años.

\subsection{Tres pecados primordiales}

Las cifras que acabamos de ofrecer producen vértigo, y no se pueden asimilar, como no se puede asimilar que se haya desembolsado por la adquisición de un jugador de fútbol 48 millones de dólares, la cuarta parte del presupuesto nacional del Chad - 195 millones-, país de siete millones y medio de habitantes. Por mucho que se acumulen adjetivos: escandaloso, alucinante, aberrante, $o$ sustantivos: injusticia, aberración, escándalo, la rea- lidad nos sobrepasa. Estamos ante el fracaso de la humanidad, es decir, ante nuestro propio fracaso. Y si comenzamos a usar lenguaje teológico -y lo usamos porque vida y muerte son realidades teologales primordiales - estamos ante el fracaso de la creación de Dios. Quienes provenimos de la tradición cristiana, además, tenemos que recordar que los pobres, los rostros que se esconden tras la macabra danza de los números que hemos mencionado, son los privilegiados de Dios. Visto desde lo humano, y ciertamente visto desde ese Dios, lo primero es, pues, hacer un juicio radical sobre la realidad de nuestro mundo: es pecado. E inmediatamente, la pregunta es "si participamos y en qué medida de ese pecado o si luchamos y en qué medida contra él".

El que este mundo, tal como lo hemos descrito, es pecado, no hace falta explicarlo mucho. Lo que ocurre es que el lenguaje y los conceptos que pudieran utilizarse para mostrarlo, no tienen ya fuerza, o no tienen la fuerza que tenían - victoria de los que controlan el lenguaje-. Entre los cristianos -y entre otros muchos - se hablaba hace años de "injusticia", "pecado estructural", "violencia institucionalizada"... Con ello se quería volver a las raíces pecaminosas de la realidad, a los verdaderos pecados "capitales", pecados "principales" y "principiantes", originantes. Hoy parece que ni siquiera ese lenguaje es suficiente para sacudir a los humanos ante la situación del mundo, pues el lenguaje ha sido domesticado o los conceptos que vehicula han sido declarados obsoletos. Por esa razón —de nuevo en impotencia e indefensión- vamos a intentar recuperar por otros caminos y otros lenguajes el sentimiento primario ante la aberración de esta realidad. Se trata de formular pecados que son aun más primordiales que los pecados capitales, y se trata de sacarlos a la luz de la profunda sima en que están enterrados. En mi opinión, estos pecados tienen algo de aquel pecado "contra el Espíritu santo" que denunciaba Jesús, el cual —sea cual 
fuere su contenido- no tenía remedio, remedio que hoy aparece sumamente difícil.

El insulto a los pobres. Fue un gran logro concebir, hace años, la realidad de nuestro mundo en términos dialécticos y causales. Se superó la mera yuxtaposición de ricos y pobres para comprender la realidad de la pobreza como producto de la injusticia: hay pobres porque hay ricos y hay ricos porque hay pobres. En tiempos de Puebla, 1979. así hablaban muchos. Sin embargo esta visión de la realidad no parece que ha tenido mucho éxito, y se ha relegado al lenguaje "políticamente incorrecto". Los ricos no se han dado por aludidos, y en el lenguaje cada vez se usan menos términos como "justicia" e "injusticia", para no parecer idealistas y utópicos, poco realistas y poco pragmáticos $-\mathrm{y}$ también para no aguar la fiesta a los predicadores del neoliberalismo, la globalización, la privalización - todo ello, por cierto, como colofón del triunfo de la democracia.

Hay que volver, pues, a la visión de injusticia estructural, pero, como están las cosas, antes hay que volver a una visión de la realidad todavía más primigenia. Supongamos - por hipótesis- que la yuxtaposición del rico Epulón, que banqueteaba todos los días, y del pobre Lázaro, que sólo comía migajas, no fuera causal e injusta sino simple yuxtaposición. Pues bien, aunque no fuese injusta, la diferencia entre ambos sería lo que en el lenguaje - lan sabio y creativo- suele llamarse diferencia "insultante". En otras palabras, Epulón y Lázaro no sólo producen (o deben producir) indignación y cólera por expresar una cruel injusticia - eso por supuesto-, sino que en un sentido todavía más primario deben producir el sentimiento de ser insultados: los pobres, ciertamente, y todos los que pertenecemos a un planeta en el que ocurren esas cosas. ¿No es insultante para la humanidad -y para los ciudadanos haitianos- que un ciudadano estadounidense valga lo mismo que cincuenta haitianos? Y si hemos perdido la capacidad para captar esa realidad como insultante es que lo primigeniamente humano está en trance de extinción. El agravio comparativo que supone esa diferencia insultante no es un concepto tomado primariamente del ámbito de realidad del derecho, sino del ámbito de realidad humana relacional. Ese nos parece ser, en el mundo de hoy, el primer paso lógico para superar la aberración: que sintamos el abismo entre pobres y ricos - y tantas otras cosas- como algo "insultante".
La ceguera tranquilizante. Los datos que antes hemos mencionado son públicos. A mi entender, desde 1991 las Naciones Unidas publica anualmente un informe sobre la situación de la pobreza y el desarrollo en el mundo, aunque al principio dilataron su publicación por razones políticas: el escándalo que producía en un mundo occidental y democrático, autocomplaciente y prepotente. Pero al fin lo publicaron, y desde entonces, esos datos pudieran ser - a mí me parece evidente que debieran ser- conocimiento obligatorio en universidades, colegios y escuelas; debieran ser manejados en las cartas pastorales de los obispos y en las decenas de miles de homilías en todo el mundo. Al fin y al cabo se trata de dar a conocer cómo está la creación de Dios, de poner nombre y carne al pecado que denunciaban los profetas y Jesús, de ser fieles a la ortodoxia -dicho sin ironía- de Medellín, Puebla, Santo Domingo, del Sínodo de las Américas.

Pues bien, los datos pueden, pues, ser conocidos, pero no lo son. Y surge entonces la pregunta: ¿cómo es posible que en cl mundo haya tantos conocimientos acumulados sobre cosas sofisticadísimas y no se sepa que al año mueren de hambre alrededor de 40 millones de personas? Esta ignorancia no es invencible, sino todo lo contrario, y por ello es culpable. Lo hemos dicho muchas veces: a la violación del séptimo y quinto mandamiento (no robar, no matar) sobreviene como por necesidad la violación del octavo mandamiento (no mentir). Al "escándalo" siempre sobreviene el "encubrimiento". Y debido al encubrimiento, un mundo que conoce tantas cosas no conoce las cosas fundamentales sobre la vida y la muerte en el planeta. Es el pecado de la ceguera, que condenaba Juan; análogo al del estar dormido ante la realidad, que denunciaba Antonio Montesinos.

"Desprecio", "reírse del otro", "tomadura de pelo". Perdósenos el lenguaje, pero eso es lo que se siente muchas veces cuando le hablan a uno, por ejemplo, sobre la globalización. Es claro que ésta debe ser analizada cuidadosamente, científicamente, si se quiere, y no se debe caer en la demagogia de condenar todo lo que produce y no analizar su potencial positivo. Pero nada de eso quita la impresión que podemos tener de que, cuando hablan de la globalización como de la última buena noticia, "nos están tomando el pelo".

Y más sorprende todavía que los predicadores de la globalización se extrañen de nuestra extrañe- 
za, o finjan compasión hacia nosotros porque todavía no hemos caído en la cuenta de que el mundo ha entrado en una ćpoca nueva y fantástica. Es muy cierto que con la moderna tecnología se acortan infinitamente las distancias entre la banca de Hong Kong y la de San Salvador. Pero, iestá resolviendo eso el que I 500 millones vivan con menos de una dólar al día? ¿O, al menos, está esto poniendo al mundo en la dirección correcta para que se resuelva relativamente pronto? Ya han dicho muchos claramente $-y$ científicamente - que lo que hoy ocurre es una doble globalización: la globalización de la riqueza y la globalización de la pobreza. Es cierto, pues, que aumentan las relaciones entre los ricos salvadoreños y los de Wall Street, pero aumentan también las relaciones entre los pobres del Bronx y los del Chad.

El insulto a los pobres, la ceguera culpable y la tomadura de pelo, que hemos mencionado, son pecados primordiales. Y son también estructurales, pues permean todas los ámbitos de la vida: políticos, económicos, culturales, deportivos, de entretenimiento, y no raras veces también el religioso.

Desde las víctimas esto se ve con meridiana claridad. En un libro colectivo reciente sobre la globalización, Francisco Fernández Buey afirma en el prólogo que la perspectiva, científica, pero desde abajo, que adoptan los diversos autores "permite afirmar con conocimiento de causa que este mundo nuestro del final del siglo $\mathrm{XX}$ es un escándalo"2.

\section{Una Iglesia de los pobres para el siglo XXI}

Ante este siglo XXI real, el cristianismo tiene que preguntarse qué hacer. Lo primero ya lo hemos hecho: pasar juicio sobre este mundo desde las víctimas - no de forma muy distinta a como en el evangelio de Juan la cruz de Jesús es el juicio del mundo-. Pero, más allá de eso, hay que preguntarse qué ser y qué hacer en y con ese mundo. A nuestro entender lo fundamental de la solución, que formulamos de forma conscientemente provocativa - aunque la explicaremos-, consiste en volver a Medellín, a la fe y a la Iglesia de los pobres que allí surgió. El año 1968 fue el verdadero cambio de siglo de la Iglesia latinoamericana (y universal).

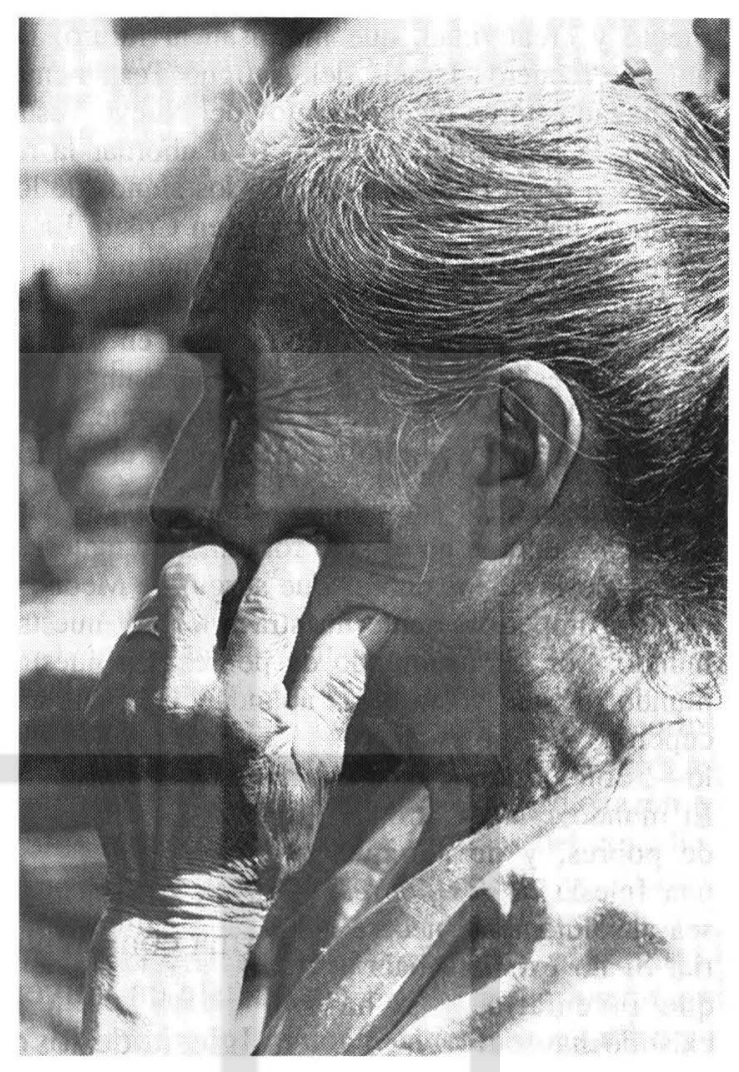

La propuesta es provocativa porque ante las novedades que se anuncian y el cambio de paradigmas, no parece adecuado enfrentar el siglo XXI volviendo a algo que tuvo lugar en el pasado. Y sin embargo, hablamos de volver porque nos parece absolutamente necesario para un continente de oprimidos y una Iglesia que debe defenderlos - por algo a Medellín lo han pretendido matar y enterrar, desde generales y oligarquías, y a su modo, también curias y jerarquías-. Además, ese pasado al que queremos volver no tiene nada de trasnochado y envejecido, sino mucho de juvenil y de nuevo en nuestros días. Y, sobre todo, Medellín sigue ofreciendo un cristianismo que es buena noticia para los pobres, los cuales, como acabamos de ver, caracterizan, también hoy, a nuestro mundo.

De todas formas, para justificar este enfoque, recordemos que a la tradición bíblico-cristiana le es esencial orientarse al futuro, ciertamente, pero eso no convierte en simplemente pasajero cualquier pasado, sino que en él puede haber funda-

2. Cristianisme i Justicia (Santander, 1999), p. 9. 
mento y creatividad, que impulsan al futuro. De ahí, el "recuerda Israel" del Antiguo Testamento, el "hagan esto en recuerdo mío" del Nuevo Testamento, la lógica del Vaticano II al abordar la renovación de la Iglesia: junto con los signos de los tiempos, hay que volver al origen en Cristo. En el eterno retorno no hay pasado, presente ni futuro. El cristianismo, sin embargo, precisamente porque toma en serio el futuro, toma también en serio el pasado, pues en él puede ( $y$ suele) haber un potencial que ilumina e inspira la historia y que, a veces, se hace imprescindible para afrontar el futuro.

La razón más importante, sin embargo, para volver a Medellín no es sólo formal, sino material: de la Iglesia de los pobres que surgió de Medellín necesita imperiosamente nuestra Iglesia y nuestro mundo, por ser un mundo de pobres. En nuestro mundo los que viven en la abundancia son la excepción -y el escándalo-. Son el mundo irreal. El mundo real es otro, el de pobres, y de ahí que una Iglesia de los pobres sea absolutamente necesaria. Si no existiera habría que inventarla, y si ha existido hay que volver a re-hacerla.

No se trata, pues, de retroceder, ni menos de caer en una cosmovisión ahistórica y mítica, según la cual la verdad ya está en el origen (W. Pannenberg). De lo que se trata es de re-cordar (volver a pasar por el corazón) y actualizar lo que de salvación puede traer hoy una Iglesia de los pobres, y como ninguna otra Iglesia puede hacerlo. Dicho en otras palabras, no entramos al año 2000 con las manos vacías, e insistimos en ello porque la (pseudo) cultura actual quiere hacernos creer que la historia y lo humano estarían comenzando prácticamente ahora. Hay cambio de paradigmas, sí, pero eso no hace desaparecer lo metaparadigmático, aquello cuya necesidad se mantiene a través de nuevos paradigmas -y la Iglesia de los pobres es una de esas realidades-. Veámoslo, analizando lo fundamental de su dimensión teologal, cristo-lógica y pneumato-lógica.

\subsection{La dimensión teo-logal de la Iglesia de los pobres}

Medellín expresa una fe específicamente teologal, al recuperar el principio jesuánico: la relación esencial entre Dios y pobres. En esto va más allá del Vaticano II y asienta las bases teologales de la Iglesia como Iglesia de los pobres.

\subsubsection{El principio jesuánico}

Vayamos directamente a lo fundamental. La Iglesia de los pobres es una Iglesia en la que los pobres son su principio interno de inspiración y organización de todo lo que ella es y hace. Eso la convierte en una Iglesia teologal, en una Iglesia del Dios revelado - Dios de los pobres-, del Dios de Jesús. En efecto, en la manifestación de ese Dios en los profetas y en los salmos, en el Magnificat y en Jesús, aparece como algo central la relación (transcendental) entre Dios y pobres. "Padre de huérfanos y viudas es Dios", repiten los salmos. La verdadera confessio Dei de Israel, se ha llegado a decir, consiste en estas palabras: "En ti el huérfano encuentra compasión" (H. Wolf).

A esa correlación entre Dios y pobres es a lo que llamamos el principio jesuánico: "Dios ama y defiende al pobre por el mero hecho de serlo", y de esa manera, el pobre queda elevado a realidad teologal, y no permanece sólo como objeto de ética u ocasión para la espiritualidad. En este sentido se puede decir que, en Europa, la tradición luterana sobre todo, hizo central el principio paulino: "Dios justifica al impío por gracia", y ello tuvo un influjo - aunque con retraso en la Iglesia católica- en la visión de la Iglesia y de su misión. En América Latina se ha insistido —como contribución suya específicaen el principio jesuánico.

Así lo proclamó sorprendente y audazmente Puebla, en 1979, en palabras que no han sido asumidas por la mayoría de iglesias y teologías, sino 
que, cortés o vergonzantemente, han sido ignoradas, cuando no enterradas (lo cual, por sí sólo, ya justificaría el tener que volver atrás). Dice Puebla: "Los pobres merecen una atención preferencial, cualquiera que sea la situación moral o personal en que se encuentren. Hechos a imagen y semejanza de Dios para ser sus hijos, esta imagen está ensombrecida y aun escarnecida. Por eso Dios loma su defensa y los ama" (n. 1142). Y en lenguaje sistemático así lo formuló Ignacio Ellacuría: "La unión de Dios con los hombres, tal como se da en Jesucristo, es históricamente una unión de un Dios vaciado en su versión primaria al mundo de los pobres"

Quiénes son esos pobres no se puede definir sin tener en cuenta la historia concreta, pero tampoco es difícil describirlos en lo fundamental: pobres son aquellos y aquellas para quienes vivir es una pesadísima carga, que carecen de dignidad y son rechazados y despreciados, que no tienen una palabra que pronunciar, en definitiva, que no cuentan en la sociedad. En tiempo de Jesús se agrupaban en cuatro grandes grupos: pobres-miserables, enfermos, pecadores-publicanos, mujeres. En la actualidad, el concepto fundamental de pobres, como los cercanos a la muerte lenta de la pobreza y a la muerte rápida de la represión, debe incluir explícitamente a las mujeres (doblemente pobres en lugares de pobreza), indígenas, afroamericanos, miembros de culturas y religiones oprimidas. Según tiempos y lugares, hay que añadir a los refugiados, despreciados por su orientación sexual, a los excluidos...

La conclusión es que, tanto por razones históricas actuales - la pobreza mayoritaria en el mundo - como por razones de identidad cristiana - la relación esencial entre Dios y pobres-, la Iglesia deberá ser Iglesia de los pobres que surgió en Medellín.

\subsubsection{Medellín como concreción y superación del Vaticano II}

Para enfatizar, sobre todo para el primer mundo, la importancia del principio jesuánico, redescubierto eficazmente en América Latina, comparemos brevemente el Vaticano II y Medellín. No es necesario encarecer la importancia del concilio y - por cierto - también la necesidad de volver a él, ni tampoco es necesario recordar que sin el concilio Medellín no hubiese sido posible. Pero dicho esto, hay que constatar una importante diferencia entre ambos por lo que toca a la relación entre Dios y pobres, que influirá decisivamente en la comprensión de la Iglesia. E insistimos en ello porque, en nuestra opinión, para defenderse de la involución actual, con tintes cada vez más autoritarios, es normal hablar de "volver" al Vaticano II -y con razón-. Allí se encuentran valores que están ahora desapareciendo al interior de la Iglesia: apertura y diálogo con el mundo, indicios de derechos humanos y de democracia dentro de la Iglesia, colegialidad...

Sin embargo, en el Vaticano II no apareció lo que hemos llamado principio jesuánico, que tiene un dinamismo distinto: el que proviene de la centralidad del pobre. Decimos esto porque, en mi opinión, algo sorprendente ha ocurrido en iglesias y leologías del primer mundo: con toda razón y necesidad han celebrado los 35 años del concilio, pero prácticamente han pasado por alto los 30 años de Medellín. Y no se diga que Medellín es "local" mientras el Vaticano II es "universal", pues, históricamente, también fue "local" para el primer mundo. Y, sobre todo, desde la fe cristiana, el principio jesuánico es universal. Por esa razón, no por minusvalorar el Concilio, por supuesto, veamos cómo éste trató el tema de la Iglesia de los pobres.

Es sabido que Juan XXIII y el cardenal Lercaro hablaron decididamente a favor de la Iglesia de los pobres, pero la idea no prosperó. Cierto es que $L G$ 8 recuerda que Cristo predicó en pobreza y evangelizó a los pobres, de modo que "la Iglesia es llamada a seguir ese camino", a lo que hay que añadir breves textos de $G S 1$ y $A d G 5$. También es cierto que después de la memorable intervención del cardenal Lercaro sobre la Iglesia de los pobres la asamblea estalló en uno de los más vivos aplausos. Y también hay que recordar que un pequeño grupo de obispos escribió un documento en el que se comprometían a hacer una opción por los pobres y a vivir la pobreza eclesial. El documento fue llamado "pacto de las catacumbas", porque en ellas fue escrito, y fue llamado también "Esquema IV", sugiriendo que merecía ser el último docu-

3. "La Iglesia de los pobres, sacramento histórico de liberación”, ECA (octubre-noviembre de 1977 ) 717. 
mento del Valicano II. Hubo, pues, asomos, semillas de una Iglesia de los pobres, pero nada más. Y en el concilio no prosperaron. Para ello hubo que esperar a que Medellín recibiese creativamente y superase al Concilio ${ }^{4}$.

Varias fueron las razones para ello, pero, visto de la perspectiva teo-logal en la que ahora estamos, la fundamental fue el modo diferente en que las iglesias y las teologías, europeas y las latinoamericanas, fueron comprendiendo los "signos de los tiempos". Simplificando un poco las cosas, en Europa se comprendieron más en el sentido que hemos llamado histórico-pastoral que tienen en la GS 4: "conocer y comprender el mundo en que vivimos, sus esperanzas, sus aspiraciones y el sesgo dramático que con frecuencia le caracteriza". Cuán necesario y novedoso fue esto para la misión de la Iglesia tras siglos de no hacerlo, es evidente: sin conocer al mundo y sin la honradez de tomarlo en cuenta, no se lo puede evangelizar.

En Medellín, sin embargo - dicho con mayor precisión: en la teología y el magisterio episcopal que surgieron alrededor de Medellín-, los signos de los tiempos fueron comprendidos $-\mathrm{y}$ esto fue lo novedoso en relación a las iglesias y teologías posconciliares del primer mundo- tamhién en el sentido históri-

La conclusión es que, tanto por
razones históricas actuales -la
pobreza mayoritaria en el mundo-
como por razones de identidad
cristiana - la relación esencial entre
Dios y pobres-, la Iglesia deberá ser
Iglesia de los pobres que surgió
en Medellín.

vigor inigualable, como lo que caracteriza al continente, sí; pero, sobre todo, habla de ello, y con radical novedad, como lugar de presencia de Dios. De esta forma, Medellín intuyó y reformuló lo que hemos llamado el principio jesuánico -que Puebla formuló después con toda claridad-. La explicitación teológica de la intuición fue obra de teólogos, con Gustavo Gutiérrez a la cabeza. Pero poner en relación teo-logal a Dios y pobres es el logro de Medellín. En los pobres está Dios. Y podemos preguntarnos si ha habido algún concilio en la historia de la Iglesia que lo haya dicho.

Al elevar pobres y pobreza a la dimensión teologal para nada se minusvalora su dimensión histórica, sino todo lo contario. Y por eso, el primer documento de Medellín —reunión de obispos, no lo olvidemos - puede comenzar sin mencionar para nada ni a Dios, ni a Cristo, ni al Espíritu ni a la Iglesia $-y$ hasta el día de hoy sus palabras producen escalofríos: "Existen muchos estudios sobre la siluación del hombre latinoamericano. En todos ellos se describe la miseria que margina a grandes grupos humanos. Esa miseria, como hecho colectivo, es una injusticia que clama al cielo" (Justicia 1). Una lectura precipitada podrá ver aquí signos de los tiempos sólo en su sentido histórico-pastoral. Pero la totalico-teologal que tienen en la GS 11: "discernir en los acontecimientos, exigencias y deseos... los signos verdaderos de la presencia o de los planes de Dios".

Estas palabras, si se las toma en serio, son poderosas. No se trata ya sólo de atinar a cómo es la realidad del mundo, para mejor actuar eclesialmente, sino de atinar en qué realidades de este mundo se hace presente Dios. La afirmación es audaz, pero, a mi modo de ver, eso es lo más central de los signos de los tiempos: existen lugares de Dios en la realidad. Lo que hizo Medellín fue nombrar esos lugares históricos de Dios. De ahí que Medellín habla de pobres y pobreza, y con dad de Medellín y el tipo de fe que generó los convierten en signos histórico-teologales: Dios es el que escucha el clamor de los oprimidos, y en esos clamores y anhelos está Dios.

La conclusión es que Medellín, al haber elevado a los pobres a realidad teo-logal, posibilita una Iglesia cuya identidad está enraizada en los pobres. Aquí está la raíz de una fe y de una Iglesia que puede superar radicalmente - desde Dios- el malestar eclesial, el actual "invierno eclesial", en este cambio de siglo. El malestar suele expresarse al interior de la Iglesia como falta de libertad, como injusticia hacia los laicos y hacia la mujer sobre todo, como dificultad con la inculturación...

4. Cfr. Teófico Cabestrero, "En Medellín la semilla del Vaticano II dio el ciento por uno”, Revista Latinoamericana de Teología 46 (1999) 59-73. 
Pero quizás lo más crudo de ese invierno es que, a pesar de muchísimas palabras y documentos, la Iglesia, con frecuencia, no acaba de volcarse a los pobres, no arriesga mucho - ciertamente no su vida, su poder y su riqueza- por ellos. Y es que la Iglesia no acaba de ver a Dios en ellos.

Y una última observación. Desde una Iglesia, teologalmente de los pobres, el extra ecclesiam nulla salus bien puede transformarse en el extra pauperes nulla salus, menos ofensivo que la Unam Sanctam de Bonifacio VIII, de 1303, o que el concilio de FlorenciaFerrara de 1442, y más cristiano. Dicho eclesiológicamente, y sin reduccionismos, extra pauperes nulla ecclesia.

Esto es lo más importante de Medellín. No se ve en el horizonte nada que pueda sustituirlo, ni tampoco en el pasado, ni siquiera, como hemos dicho, en el Vaticano II's. Por eso proponemos volver a Medellín.

\subsection{La dimensión cristo-lógica de la Iglesia de los pobres}

De cara al siglo XXI creemos que sólo una Iglesia que "se parece a Jesús" tendrá credibilidad, y así tendrá también posibilidades. Al menos de palabra, "Jesús cae bien a (casi) todo el mundo": a personajes como Gandhi y Fidel Castro, a las mayorías pobres y a las mujeres que buscan la dignidad que les han arrebatado. Los pobres de Asia, cientos de millones, no tienen ningún problema con Jesús de Nazaret, repite A. Picris, quien, por cierto, da como razón algo semejante a lo que hemos llamado el principio jesuánico, hecho realidad en la misma vida y persona de Jesús. "La afirmación de fe de que Jesús encarna el pacto defensor entre Yahvé y los oprimidos constituye una cristología que puede traducirse en una praxis en Asia, y de hecho también en cualquier otra parte del mundo. Tan sólo esta praxis convierte al cristianismo en una religión universal".

Pues bien, la Iglesia de los pobres "se parece a Jesús", o, al menos, tiene mayor parecido que otras, y por eso tiene futuro. Para mostrarlo en su punto álgido, baste mencionar a los mártires: en esa Iglesia ha habido muchos mártires, y con la peculiaridad de que, en lo sustancial, vivieron por la causa de Jesús (el reino), con los valores de Jesús (anuncio y denuncia, libertad y fortaleza) y fueron dados muerte por las mismas razones que Jesús (defensa de los oprimidos en contra de sus opresores). Veamos un poco más en detalle, concentrándonos sólo en tres puntos, cómo la Iglesia de los pobres "se parece" a Jesús y cómo "remite" a Jesús.

\subsubsection{Encarnación y cruz: una Iglesia real, no doceta}

Desde el comienzo, el docetismo cristológico fue, quizás, el mayor problema para la Iglesia (W. Kasper), y recordemos que la Iglesia tardó mucho más tiempo en definir la consubstancialidad humana de Cristo (Calcedonia, 450) que la divina (Nicea, 325). Pero el docetismo es también problema eclesiológico. Podrá extrañar la afirmación, pues para la Iglesia no pareciera ser problema "ser humana", sino que el problema estaría más bien en "ser demasiado humana", pecadora también. Pero no pensamos que las cosas son tan simples. La

5. Como consecuencia histórica de vivir según el principio jesuánico surge otra diferencia importante entre el Vaticano II y la Iglesia que surgió de Medellín. Es lo relativo a la persecución y al martirio. En el concilio no son muy tomados en cuenta, fuera de la frase genérica de $L G 8$ y la alusión a quienes sufren persecución en la misiones, $A d G$ 42. A partir de Medellín, persecución y martirio fueron realidad masiva y central en la Iglesia.

6. “ ¿Universalidad del cristianismo?”, en El rostro asiático de Cristo (Salamanca, 1991), pp. 166s. 
Iglesia está factualmente en el mundo, pero tiene la innata tendencia a crearse para sí un espacio propio (doctrinal, pastoral, litúrgico...) -que la defiende del mundo-, como si esos espacios fuesen para ella "lo más real de lo real", y que le otorga poder cuasi absoluto, porque en ese su espacio sólo ella manda. Pero de esa manera se hace "irreal", y, sobre todo, no hace central lo que sí es "lo más real de lo real". Qué sea eso queda descrito en las siguientes palabras de estos días -que pueden valer por muchísimas otras - sobre los refugiados de los Grandes Lagos:

Estos seres humanos siguen siendo el deshecho de la humanidad. Son millones de personas que sobran en nuestro mundo. Nadie sabe qué hacer con ellos, y son conscientes de que no cuentan para nadie. Llevan pegada a su piel toda una historia de sufrimiento, humillación, terror, hambre y muerte. Están heridos en su dignidad... Pero este trabajo con los refugiados de los Grandes Lagos es también una invitación a confiar en el ser humano, en su capacidad de superarse aun en las peores condiciones. Es colaborar con un grupo de personas que pueden recuperar su dignidad?

Estos son los gozos y sufrimientos de los que habla la Gaudium et Spes, pero tomados en serio, no en abstracto. Pues bien, no hacer de esa realidad la realidad central para la Iglesia es lo que llamamos docetismo. Como en la cristología, esos seres humanos son la sarx (lo débil de la carne), no simplemente la neutra humanitas de las afirmaciones conciliares - aunque con dificultad tomamos conciencia de ello-. Lo hemos dicho muchas veces. La sociedad y la cultura moderna -incluida, con retraso, la Iglesia y la teología- deben mucho a la exigencia kantiana de "despertar del sueño dogmático". Pero no creo que hemos despertado lodavía de un sueño mucho más profundo, "el sueño de cruel inhumanidad", que denunció Antonio Montesinos, en 1511, en La Española, palabras dirigidas a los encomenderos españoles ante la cruel realidad en que vivían los indios: "¿cómo estáis en tanta profundidad de sueño tan letárgico dormidos?".

Este estado de "dormición", esta "irrealidad" hace a la Iglesia muy poco cristiana e irrelevante, y quienes pueden "despertarla" y "hacerla real". "darle carne real", sarx, no sólo humanitas - muy proclive ésta al poder, a la riqueza, a la vanagloria y el pecado- son los pobres de este mundo. En un ejemplo de nuestros días, de la Iglesia de Monseñor Romero se podrían decir muchas cosas, también limitaciones y pecados. Pero de lo que no se puede dudar es de que no cayó en el docetismo: fue una Iglesia salvadoreña, real. Y bien lo vio Monseñor: "Sería triste que en una patria donde se está asesinando tan horrorosamente no contáramos entre las víctimas a los sacerdotes. Son el testimonio de una Iglesia encarnada en los problemas del pueblo".

Parecerse a Jesús, superando el docetismo, no es asunto conceptual, sino que es un estar real y activamente en una realidad que es pecado, es decir, lo que da muerte, lenta o violentamente. Y parecerse a Jesús es cargar con esa realidad, y con lo que tiene de oneroso: la cruz. No hay aquí masoquismo, ni siquiera puro mimetismo místico de Cristo, sino encarnación real con todas sus consecuencias.

En conclusión, una Iglesia de los pobres, por serlo, puede ser una Iglesia que se parece a Jesús porque ha superado el docetismo. Y una Iglesia de los pobres que ha llegado hasta el martirio se parece a Jesús, porque ha cargado con la cruz. Esa es la Iglesia que desencadenó Medellín.

\subsubsection{Misión: la lucha en favor de la esperanza de los pobres}

Toda Iglesia debe tener una misión que sea fundamentalmente como la de Jesús. En lo que queremos insistir - porque se ignora con frecuencia- es en que a esa misión le es esencial una praxis agonista, es decir, conflictiva y luchadora, y una praxis que sea globalizante. Ejemplos actuales de esto son la proclamación de la verdad y el desenmascaramiento de la mentira, la denuncia de la injusticia, la defensa de los derechos humanos, propuestas - aunque sean modestas- de formas humanas de economía... Son formas de extender el reino de Dios.

No podemos analizarlas ahora, por lo que nos concentramos sólo en una: la lucha por mantener la esperanza de los pobres. Nos centramos en ella porque es una misión globalizante en favor de los

7. Teresa Florensa, Vida Nueva, 2187 (25 de mayo de 1999), p. 46. 
pueblos, porque es conflictiva y porque, en nuestra opinión, es cada vez más urgente. Repite don Pedro Casaldáliga: "Si a un pueblo le quitan la esperanza, le han quitado todo". Con ello proclama la importancia de la esperanza, pero también dice que está en peligro, "se la pueden quitar a los pueblos". Y así es. La esperanza de los pueblos es hoy objeto de una lucha, y lo importante es qué quieren unos y otros hacer con ella. Dice un economista centroamericano:

Aquellos países que han levantado la esperanza de algo nuevo, como Nicaragua y El Salvador de los ochenta, necesitaban ser no sólo destruidos sino desacreditados y convertidos en una espúrea esperanza de pueblos románticos porque rompían el proceso de homogeneización iniciado con la era Reagan*.

La conclusión es que la élite del poder promueve "la geo-cultura de la desesperanza y la teología de la inevitabilidad... La desesperanza es la actitud necesaria para la estabilidad desde la perspectiva del dominador. El desgaste de la esperanza es una necesidad del sistema".

En nuestro mundo se dan, pues, batallas no sólo para apoderarse de materias primas o espacios estratégicos, sino también para apoderarse del "alma de los pueblos", de su "conciencia colectiva". Así, en la actualidad se desea introyectar valores positivos, como la tolerancia, la laboriosidad, la competencia laboral, y otros, más negativos, como el consumismo y la diversión de evasión. Pero permeándolo todo, sutil o burdamente, se introyecta la resignación, la inevitabilidad, la desesperanza, más que la esperanza, y de esa forma se pretende privar a los pueblos de energía para reaccionar contra la historia actual y revertirla.

Entre nosotros, hace algunas décadas hubo una extraordinaria esperanza. Irrumpió como conteni$d o$ : la utopía de la vida digna y justa de las mayorías. E irrumpió como energía y fuerza subjetiva del espíritu, individual y colectiva, que daba inspiración y ánimo para emprender una praxis trans- formadora. La utopía movilizó a muchos a trabajar arduamente y a entregar lo mejor de sí mismos en esa tarea. Sólo con ideologías y estrategias, pero sin esa esperanza, no hubiesen sido posibles las revoluciones que ocurrieron en el país ${ }^{10}$.

Eso fue entonces. En la actualidad, por poner el ejemplo de El Salvador, Iras la esperanza que generaron los acuerdos de paz y el Informe de la Comisión de la verdad, comenzó a desvanecerse aquélla, y apareció el desencanto -como lo demuestran las encuestas-, y las mayorías populares han tenido que aprender a vivir con el desencanto más que con la esperanza. Además, desde las cúpulas de todo lipo (sin que las cúpulas eclesiales y religiosas hagan lo suficiente por contrarrestarlo) se introyecta eficazmente la idea de que "ha pasado el tiempo de la esperanza"; más aún, "ya hemos encontrado un camino mejor".

Eso "mejor" que nos proponen es una actitud global que se orienta en la línea del realismo y el pragmatismo, en el vivir ajustados a la realidad, para sacarle todas las ventajas posibles -en el mejor de los casos, incluso en favor de los pobres, en la intención de algunos-. No hay que negar que ello puede producir algunos bienes, pero no da cabida a la esperanza, pues ésta trae consigo, por esencia, un "desajuste". La "justeza", de la que hablaba Ellacuría, y que hoy se recalca con razón, no tiene por qué oponerse al "desajuste" que produce la esperanza, pero tampoco lo puede sustituir, pues ambas cosas responden a ámbitos distintos de realidad.

Ese realismo, que prescinde de la esperanza, no es fácil de erradicar, pues nos es impuesto, en muy buena parte, desde fuera y por fuerzas poderosas, y por ello existe una batalla alrededor de la esperanza de los pobres. En esa batalla, unos están contra la esperanza, a veces en forma directa, como hemos visto, a veces en forma indirecta, introyectando actitudes y expectativas que no la hacen necesaria, sino sospechosa. Pero en la batalla, otros están a favor de la esperanza de los pueblos.

8. X. Gorostiaga, "La mediación de las ciencias sociales y los cambios internacionales", en J. Comblin, J. I. González Faus y J. Sobrino, Cambio social y pensamiento cristiano en América Latina (Madrid, 1993), p. 131.

9. Ibid.

10. Hablamos de revoluciones en plural porque, efectivamente, éstas ocurrieron no sólo al nivel político-militar, sino también al nivel social (la organización popular), eclesial (el ministerio de Monseñor Romero, las comunidades de base) y teórico (la opción por los pobres, en varios ámbitos de la inteligencia, ciertamente en la teología de la liberación). 
Lo que está en juego es que con esperanza los pobres pueden vivir, trabajar y mantener su dignidad. Y pueden también ofrecer luz, solidaridad, salvación al primer mundo. Dicen a los pueblos de abundancia que se puede vivir y ser humanos "de otra manera", no según los valores occidentales de consumismo, individualismo, autocomplacencia, egoísmo, sino muchas veces en contra de ellos. Pero, por eso mismo, esa buena noticia, es captada también como amenaza, pues el norte ya no sería definidor, controlador y, así, dueño de lo humano. Se comprende, entonces, que se quiera eliminar la esperanza de los pobres e imponer la cultura de la desesperanza y del desencanto, y la conciencia de la inevitabilidad.

En conclusión, la defensa de la esperanza de los pobres es problema actual y urgente, y es una forma actualizada de re-hacer la misión de Jesús en favor de los pobres. Una Iglesia que lucha por esa esperanza se parece a Jesús. Y eso ocurre mejor en una Iglesia de los pobres que en otras.

\subsubsection{Evangelización: la buena noticia de Jesús}

Ahora vamos a hablar no ya de parecerse a Jesús sino de a qué Jesús quiere parecerse la Iglesia, y, en consecuencia, a qué Jesús quiere anunciar. La Iglesia siempre tiene que evangelizar. Tiene que anunciar a Dios y a su Hijo Jesucristo, y todo ello en totalidad. Pero no es ocioso preguntarse cómo y por dónde empezar a anunciar la buena noticia; en otras palabras, qué de Jesús la impacta de verdad. Pues bien, no sería malo comenzar por el sumario de los sinópticos: "acudían a él de todas partes". Jesús era buena noticia, pues a él acudían. Pero es esencial recordar que quienes acudían eran las mayorías, los pobres (ochloi, en griego, masas, con cierto matiz despectivo). Algo impactaba de Jesús a los pobres, que lo veían como buena noticia.
Pensando en nuestro mundo de hoy, ¿qué es lo que hoy impacta de Jesús, que lo convierte en buena noticia? La respuesta es importante, pues en un mundo en vías de secularización, por un lado, y de desencanto, por el otro, no basta que la Iglesia repita doctrinalmente el contenido de la fe en Cristo, sino que hay que presentarlo en su capacidad de humanización, en su atractivo para las mayorías. Desde las narraciones evangélicas y desde la experiencia de los pobres y víctimas, quizás podemos decir lo siguiente".

De Jesús impacta la misericordia y la primariedad que les otorga: nada hay más acá ni más allá de ella, y desde ella define la verdad de Dios y del ser humano. De Jesús impacta su honradez con lo real y su voluntad de verdad, su juicio sobre la situación de las mayorías oprimidas y de las minorías opresoras: ser voz de los sin voz y voz contra los que tienen demasiada voz, e impacta su reacción hacia esa realidad: ser defensor de los débiles y denuncia y desenmascaramiento de los opresores. De Jesús impacta su fidelidad para mantener honradez y justicia hasta el final, en contra de crisis internas y de persecuciones externas. De Jesús impacta su libertad para bendecir y maldecir, acudir a la sinagoga en sábado y violarlo, libertad, en definitiva, para que nada sea obstáculo para hacer el bien. De Jesús impacta que quiere el Toda Iglesia debe tener una misión que sea fundamentalmente como la de Jesús. En lo que queremos insistir - porque se ignora con frecuenciaes en que a esa misión le es esencial una praxis agonista, es decir, conflictiva y luchadora, y una praxis
que sea globalizante. fin de las desventuras de los pobres y la felicidad de sus seguidores, y de ahí sus bienaventuranzas. De Jesús impacta que acoja a pecadores y marginados, que se siente a la mesa y celebre con ellos, y que se alegre de que Dios se revela a ellos. De Jesús impactan sus signos - sólo modestos signos del reino- y su horizonte utópico, que abarca a toda la sociedad, al mundo y a la historia. Finalmente, de Jesús impacta que confía en un Dios bueno y cercano, a quien llama Padre, y que, a la vez, está disponible ante un $\mathrm{Pa}$ dre que sigue siendo Dios, misterio inmanipulable.

11. Reproducimos aquí lo que escribimos en La fe en Jesucristo. Ensayo desde las víctimas (San Salvador, 1999) p. 309s. 
Ver hecha realidad en una persona cada una de estas cosas, honradez y verdad, misericordia y fidelidad, libertad, gozo y celebración, pequeñez de lo inmediato y grandeza de la utopía, confianza en el Padre y disponibilidad ante Dios, es siempre una brisa de aire fresco. Ver a gente así es una buena noticia. Pero impacta también, y quizás más que lo anterior, el que en una misma persona aparezcan unidas cosas difícilmente unificables. Jesús es a la vez hombre de misericordia (misereor super turbas) y de denuncia profética ("ay de ustedes los ricos"), hombre de reciedumbre ("quien quiera venir en pos de mí, tome su cruz y sígame") y de delicadeza ("tu fe te ha salvado"), hombre de confianza en Dios ("abba, Padre") y de soledad ante Dios ("Dios mío, "por qué me has abandonado?").

$\mathrm{Y}$ así pudiéramos seguir. Lo importante es que - sea cual fuere la fortuna de la descripción anterior- los evangelios presentan a un Jesús encarnando todo lo que es más humano y simultaneando todo lo que sea humano. La Iglesia debe presentar a un Jesús así, y debe socializar la buena noticia - a ejemplo de Jesús- en la mesa compartida, donde también para los pobres haya manteles largos y taburetes. Pero ver a Jesús de esa manera y hacer central en la Iglesia la mesa compartida, necesita de los ojos y de la esperanza de los pobres, de "los que acudían a él de todas partes". Y eso lo puede hacer una Iglesia de los pobres mejor que otras.

\subsection{La dimensión pneumato-lógica: vivir ya como resucitados}

La expresión es audaz, pero se trata de preguntarnos si en la historia y a la manera histórica, la Iglesia puede vivir ya como resucitada, participar en un como reverbero de lo que en la resurrección de Jesús hay de plenitud y de victoria. A esto llamamos la dimensión pneumatológica, porque expresa la vida nueva que se adjudica al Espíritu. Y la formulamos así para evitar exageraciones espirituales, porque vivir así, no trasladados a realidades vaporosas, es vivir con espíritu.

Desde un punto de vista histórico y social, esa nueva vida puede ser hoy descrita como una civilización en la que el trabajo tenga prioridad sobre el capital (lo que repite Juan Pablo II), a lo que Ignacio Ellacuría añadió una "civilización de la pobreza" en contra de la actual del capital, como única forma de hacer posible hoy "la civilización del amor". Esta civilización de la pobreza no significa, obviamente, aceptar ni menos fomentar pauperismo y miseria. Pero expresa, escandalosamente, la convicción cristiana de que desde los pobres y su mundo surge con mayor naturalidad el espíritu que humaniza a todos, intuición jesuánica central en los evangelios. Pues bien, la Iglesia de los pobres - y los pobres en la Iglesia - pueden ser como sacramentos de esa nueva civilización de la pobreza.

Dimensiones esenciales de esa Iglesia resucitada en la historia son la esperanza, la libertad y el gozo. La resurrección dice esperanza, una esperanza que es en directo para las víctimas, no para todos por igual, pues Dios resucitó, hizo justicia, a una víctima y no a un victimario, ni siquiera simplemente a un cadáver. Lo que tiene de buena noticia no es simplemente el anuncio de una vida más allá de la muerte - lo que también esperaban egipcios y griegos-, sino una esperanza cualificada: que el verdugo no triunfará sobre la víctima. Por definición, una Iglesia de pobres y víctimas es la que mejor capta esa esperanza específica. Y esa esperanza mayor de las víctimas se hace real en otras pequeñas esperanzas del día a día de los pobres.

Y junto a la esperanza, la lglesia de los pobres puede expresar también la libertad y el gozo del resucitado, con lo que terminamos. No es la libertad liberal, sino la que surge de la compasión hacia el pobre, la de Jesús, para la cual —por nacer 
de la compasión - nada es obstáculo para hacer el bien. Esa libertad es plenitud, pero es también victoria sobre el egoísmo y el miedo, que son las ataduras de la historia que quitan libertad. Y es gozo, como el de Jesús, cuando los pequeños entienden los misterios del reino y prosperan sus causas, pequeñas o grandes. Ese gozo de nuevo es plenitud, pero también es victoria sobre la tristeza, producto cuasi inevitable del sinsentido de la existencia.

"No toda vida es ocasión de esperanza, pero sí lo es la vida de Jesús, quien, por amor, cargó sobre sí la cruz", dice Jürgen Moltmann. Quizás se puedan aplicar estas palabras, con modestia, a una Iglesia de los pobres. Encarnada, evangélica, profética y crucificada, puede ser también una Iglesia que da esperanza, una Iglesia resucitada: con libertad y gozo. Esa Iglesia es la que se parece a Jesús. Y esa Iglesia - y, en lo fundamental, sólo esa Iglesia- es la que podrá humanizarnos en el siglo XXI.

\section{4. ¿Es posible esa Iglesia de los pobres?}

Al terminar estas reflexiones surge la pregunta obvia. ¿Es posible volver a la Iglesia de los pobres? Dicho con mayor precisión, ¿es posible re-hacerla, historizarla adecuadamente en el siglo XXI? Ciertamente, las cosas han cambiado en el mundo y en la Iglesia, pero hay que estar claros en dos puntos fundamentales. El primero es que la Iglesia de los pobres ha sido una realidad, no un deseo o un puro concepto de una determinada teología - cosa que no ocurrió en esa medida con la Iglesia surgida del Vaticano II-. Y si esa Iglesia ha sido real, entonces, en princinio, es posible. Y el segundo es que la razón fundamental de su existencia real ha estado en la misma Iglesia. Algo ayudó el ambiente social y político de la década de los sesenta, pero no hay que exagerar el argumento. Como repite Gustavo Gutiérrez, rebatiendo opiniones contrarias, "la segunda mitad de la década de los sesenta no fue de un fácil optimismo"'2. Y, una vez surgida, esa Iglesia fue amenazada de muerte.

La posibilidad de la Iglesia de los pobres es intrínseca a una determinada fe teologal y cristológica. Esa posibilidad se hizo real y se tradujo en una increíble y novedosa configuración de los diversos estamentos del cuerpo eclesial. Surgió una generación de obispos, casi sin paralelo en la historia de la Iglesia, junto a grupos sacerdotales, de religiosas y religiosos, simbolizados en la CLAR. Y lo fundamental es que surgió una nueva configuración de la fe desde abajo: desde las comunidades populares cristianas de base. Todo ello fue acompañado por una creatividad desconocida en el magisterio episcopal, con sorprendentes cartas pastorales, una teología - la de la liberación-, una pastoral y una liturgia... Y esa Iglesia produjo mártires jesuánicos, parecidos a Jesús, lo que rara vez ha ocurrido en la historia. La Iglesia de los pobres ha sido, pues, una realidad suficientemente masiva y de gran calidad evangélica, aun teniendo a los poderes de este mundo en su contra. Y la razón fundamental, creemos, es que puso a producir jesuánicamente el evangelio de Jesús.

En la actualidad, los poderes de este mundo siguen estando en contra de esa Iglesia o se congratulan de haberla casi destruido. Pero recordémoslo: el evangelio sigue teniendo una fuerza intrínseca para devolverla a la vida. Por ello nos parece un error apelar - con cierta simpleza- a los cambios de paradigma para dictaminar que hoy ya no es posible. Lo que sí se deduce de lo dicho es la grave responsabilidad de la jerarquía, del Vaticano sobre todo, y de todos para alentar y no destruir esa Iglesia, para tenerla presente en el nombramiento de obispos, en la dirección de seminarios, en la promoción de laicos y laicas comprometidos en la línea de Jesús. En conclusión, la grave responsabilidad de no dificultar, sino propiciar su crecimiento —así como de hecho se ha tolerado o propiciado el crecimiento de movimientos espiritualistas-

Nuestra propuesta de volver a la Iglesia de los pobres no desconoce las dificultades. No es, pues, ingenua, pero sí convencida. En lo que sí hay que estar claros es que ese volver implica trabajar y luchar, implica praxis e implica volver a insistir en la dimensión agonista del cristianismo, ahora tan relativizada, cuando no enterrada. En una palabra, implica seguimiento de Jesús. Digámoslo con la máxima radicalidad: ese volver implica santidad,

12. "Actualidad de Medellín", Revista latinoamericana de Teología 45 (1998) p. 223. Y recuerda la activa presencia de dictaduras en Haití, Paraguay, Nicaragua, los gobiernos de seguridad nacional en el cono sur, la violencia guerrillera en Colombia, Venezuela, Perú, Bolivia, la matanza de Tlatelolco, la inestabilidad y los graves problemas sociales en varios países. 
de la que Ellacuría decía que es "la última arma de la Iglesia de los pobres".

Terminemos. Es posible que el mundo se canse $y$ hastíe de su actual deshumanización, y es posible que la Iglesia pase de la involución a la apertura, del miedo a la buena noticia. Pero sea de esto lo que fuere, no hay excusa para no trabajar y luchar por volver a la Iglesia de los pobres. Nuestra esperanza es que esa Iglesia volverá a resurgir — con las novedades que se han ido gestando en estos años: liberación y presencia de la mujer, del indígena, del afroamericano, de la ecología, y con otras todavía no conocidas, pero volviendo siempre a lo fundamental.
En un artículo reciente J. Comblin, nada ingenuo, reconoce que el panorama eclesial actual es bastante desolador, si se lo compara con Medellín. Pero concluye con estas palabras:

¿Habrá otro acontecimiento? Aún no lo sabemos. Por el momento no acontece nada. Pero algo puede suceder que cristalice todas las fuerzas latentes. La Iglesia de los pobres está latente. Una nueva circunstancia puede sacarla de nuevo a la superficie de la historia. Medellín reaparecerá mañana, como nuevo acontecimiento eclesial ${ }^{13}$.

13. “Medellín ayer, hoy y mañana”, Revista Latinoamericana de Teología 46 (1999) p. 81. 